\title{
Psychological Strategies in the Process of Pitching New Business Opportunities
}

\author{
OLEG REDKO \\ Department of Economic Theory, \\ Kyiv National Economic University named after Vadym Hetman \\ Oleksandra MoskalenKo \\ Department of Economic Theory, \\ Kyiv National Economic University named after Vadym Hetman
}

\begin{abstract}
This article reviews psychological strategies that lead to revealing the potential of new business opportunities. One of the most effective means of finding investments is the art of right pitching. The procedure of persuading one to invest into a project is a soft skill with an interdisciplinary approach. One of the factors of successful pitching is choosing the right strategy. This theoretical paper addresses the question by analysing the strategies and psychological factors of a successful pitching process. The purpose of this article is to give the directions of how to build soft skills of pitching in the most efficient way. There has been made an analysis of the recent research in the field of pitching strategies and psychological factors. The findings of this paper show the effectiveness of uniting all the pitching strategies into one and contributes to the practical field of pitching.
\end{abstract}


Keywords: pitching, investors, signals, argumentation, psychological strategies, rhetoric, persuasion

JEL Classification Codes: M13, M 21, O10

\section{Introduction}

Modern entrepreneurial goals are mostly to bring investment into new innovative projects and start-ups. New projects of any type are always a risky and psychologically complicated "to sell". Psychological strategies of pitching ideas in the right way are the main soft skill which is analysed and studied now by many researchers. This article underlines the main strategies and aspects in the modern range of pitching technics and foundations, while strategies are classified into different categories and types.

There are analytical narrative methods which use the right rhetoric and give an opportunity to get plausibility and resonance (Werven et al., 2019). Additionally, there is a need to analyse the type of investors, there is a need to know the "final customer" and how he or she will react to one or the other chosen strategy (Williams, 2013). Thus, the work for creating the right pitch is not just conducting it in an intrinsic way, but also by getting to know the people one is going to try to persuade. Some investors look for quantitative analysis of the projects before issuing the needed finances, and some are more concentrated on the managerial aspects of a possibly successful project (Mullainathan \& Shleifer, 2005). Some investors are looking for well written business plans, registered patents, and created prototypes, which serve as a supporting effect in the pitching process and serve as intellectual capital signals (Krukowski, 2019).

To create the right made-to-measure pitching process for investors, there is need of rigorous linguistic analysis, there is need to understand if to use the right metaphors or to delete them from pitching, seek and find the right level of language complication or simplification and even the syntax, which are all the factors affecting investors' decisions to go into a new entrepreneurial adventure or to stay away from it (Cunningham, 2010).

The goal of this article is to give entrepreneurs who try to persuade investors to go into their new projects the needed directions of how to build their soft skills of pitching in the most efficient way possible and how to have a stronger effect on the investing audience. It will be proved that even such factors as the acoustic charisma (Niebuhr et al., 2017) are as important as all the other factors to build the perfect puzzle of this entrepreneurial phenomenon called pitching.

The culture of promoting ideas and propositions in the most efficient way as possible is something that has become a new trend in the field of angel investment, 
management, education, social issues, differentiated industries, marketing, and also in the field of science and research ideas competing in the race for the most psychologically viable oriented pitching tactics. There were conducted many studies in this field, in this work there are mentioned scientific papers of researchers like Susan J. Ashford and James R. Detert (2015), Sarah Bloomer and Rachel Croft (1997), Robert W. Faff (2017), Roger Altizer and Jr. José P. Zagal (2014), Christopher Wickert and Frank G.A. de Bakker (2015), Rola El Habbal Jadayel and Karim Medlej (2018), John F. Sherry Jr. (2018), Gary Peacock (2016), Peter Ellis (2016), Andrew Maxwell (2017), Donna Meiklejohn (2017), Kipp Anthony Krukowski (2019), Luke Pittaway (2010), Laura Cunningham (2010), Sendhil Mullainathan (2005), Andrei Shleifer (2005), Nazila Babakhani (2017), Robin Carrick (2017), Angel Chen (2017), Kathy Dallest (2017), Lisa Daunt (2017), Marisol Escobar (2017), Gabe Foley (2017), Chelsea Gill (2017) and others.

\section{Psychological strategies in the process of pitching}

For constructing the right made-to-measure pitching process, it is necessary to put in the spot a line of different aspects of psychological strategies. These strategies force the process of pitching and give effect in the final goal, which is to persuade investors. The range of aspects this article touches upon can be a right business plan, a right linguistics or, as an example, psychologically adapted metaphors.

The subject-matter of such an interdisciplinary approach as pitching is that all the psychological approaches and methods are separated into different disciplines and have different aspects (quantitative, linguistic, etc.). This research tries to unite all the methodology into one theoretically applied instruction. Such a theoretical study will give entrepreneurs a possibility of having a more complex and effective approach to apply. Unfortunately, the entrepreneur who is making a pitch can have a slightly cut strategy. The pitching of such an entrepreneur can be well-prepared from the point of view of visuals and having a great quantitative part of the business plan, but he or she might lack the right linguistic approach. Moreover, such an entrepreneur can have a great linguistic approach, but may forget to prepare the right quantitative analysis for making the right persuasive signal in this field. What this study can prove is that the lack of a complex and comprehensive approach leaves the pitching process half-done and less effective in its strategy and psychological influence on the investor.

To apply psychological strategies in the process of pitching, there is a need to use different research and unite it into one full and systematic strategy. There are very effective studies, specific in their science, which were used in this research, such as 
the work of Ruben van Werven, Onno Bouwmeester, and Joep P. Cornelissen, who go into the micro-level rhetoric in their article "Pitching a business idea to investors: How new venture founders use micro-level rhetoric to achieve narrative plausibility and resonance". Moreover, this article was enriched by the research of the "types" of investors, made by Alexander Williams at the MIT Sloan School of Management. Many useful studies were conducted on this theme by such scientists as Kipp Anthony Krukowski, Luke Pittaway, Laura Cunningham, Sendhil Mullainathan, Andrei Shleifer.

To embrace the understanding of the psychological factor in pitching, there is a need to underline the fact that each persuasion has a multilayer strategy which leads to a psychological effect. There is verbal and non-verbal communication, combined with visuals and a business plan ready to be implemented, also there is the linguistic part of the complexity of persuasion to have right argumentation (quantitative or qualitative) and to give the right signalisation. Thus, to create an instructional and rather practical strategic plan, all the components and how to combine them in the process of pitching an idea need to be mentioned.

First of all, it is urgent to go to the basics and define the "type", also known as the "personality", of the investor. Be acquainted with one's audience and their perception of information is a basic thing to do, i.e., to choose the best psychological strategy to pitch the idea. "Presentation may affect investors with various personality types, so this approach may provide a valuable insight to entrepreneurs seeking venture funds. For example, an entrepreneur's presentation, relative to the executive summary, will have significantly less influence on an investor who focuses on opportunity over the entrepreneur than it will influence one who focuses more on the entrepreneur" (Williams, 2013, p. 25).

It is essential to use a strategy which will be covering the work with investors before a pitch, during the pitch and presentation of the idea, and also after the pitch assessment. "The results show that it seems plausible that investors have views on the importance of team versus other attributes, such as ideas, markets, and risks, and those ideas manifest themselves in the choices investors make during the abstract review of business documentation. Interestingly, however, during a pitch, venture investors seem sometimes to be unable to disentangle opportunity and team in any coherent and traceable way. In other words, it is essentially impossible to differentiate the content of the pitch from the delivery of the pitch" (Williams, 2013, p. 41).

After defining the psychological picture of the investor and dividing the work with the investor into three different parts (pre-pitch, pitch and after-pitch assessment), there comes the next step, which is modeling the first stage of persuading the investor: business plan development. It is a basic document, which will be written, tested, re-written, composed into the presentation and other visuals, will have its visual, linguistic, and also financial conjecture parts and will be worked through 
much before even being presented to the investors. It is the minimum prerequisite before going into a pitching process and it should contain the main points which will be used during a pitch (Cunningham, 2010).

After defining the investor's personality and preparing the right business plan, the next stage contains the right usage of linguistics, persuasion technics, and the right signalisation towards the investors. "Factors related to the entrepreneur's style of delivery had the largest influence, despite the tendency of the business angels to attribute their decisions to content-oriented, non-presentational criteria such as the soundness of the business plan, the level of information provided, and clarity of the pitch. This gap between what the investors thought made a difference in their decision and the findings of the study demonstrating that presentational factors had a larger, yet outwardly denied, effect. This demonstrates that there are factors at play on the subliminal level that work in conjunction with persuasion" (Cunningham, 2010, p. 19). The entrepreneur, knowing that there are subliminal factors that affect the decision-making of investors, has to work on his or her pitch from the point of view of charisma (so as to create an effect of passion on the part of the pitching entrepreneur). Charisma, as one study shows, has its characteristics related to the tone of voice and how the pitching entrepreneur is using his/her natural skill of speaking. A tone of voice which is fluent, rich, flexible, firm, sweet, durable, and at the same time deep, full, clear, and flawless, creates a charismatic atmosphere which will make an ultra-effect on the investor (Niebuhr et al., 2017). It is, therefore, advisable to operate with the subconscious factors of investors and create the effect of passion around a given pitching technique. For instance, Cunningham suggests that "Passion is one of the most frequently observed aspects of the entrepreneurial process and is a strong indicator of motivation" (Cunningham, 2010, p. 19).

It is worth operating with the systems of beliefs of the investor. To ask the main question of: What exactly does the investor want out of this investment? What is driving him/her to invest? When developing a psychological strategy for successful pitching, there is a need to go through the understanding of the investor's personality, development of a good business plan, working with one's voice and the creation of the "passion and motivation" effect and now it is needed to dig into the ideology of the investor and the belief which is driving him/her towards becoming an investor in any business, the pitcher trying to work with his/her deep personal psychology (Mullainathan \& Shleifer, 2005). "More generally, to extract specific predictions of the behavioral model, we make assumptions about beliefs and how they change over time. We propose that people hold in their minds two very different - and often conflicting - systems of beliefs about investing. We can describe these systems as growth (investment as a way to make money) and protection (investment as a way to secure the future). Growth is associated with wealth, independence, enjoyment, and 
freedom to do the things one likes. Protection is associated with security, insurance against ill health and poverty, and freedom from adversity. Growth and protection are intimately related to greed and fear as well as to return and risk" (Mullainathan \& Shleifer, 2005, p. 8).

When creating a psychological strategy of pitching, it is recommended to take up in advance the work with the content of the pitch. Even by having the best visuals, great voice adaptation and making a full psychological portrait of the investor, it is essential to put the process of investing effort into analysing and preparing the narratives and its content delivered to the investors. The content is made by creating a line of truthful arguments, strongly underlining the positive side of the investment. The pitching process has to come down to the micro-level arguments, giving the picture of the marketing situation, the environment which the product is dedicated to, the management side and other content which can be called solid at this stage of business development (Werven et al., 2019).

One of the strategical things to mention in this research is the existence of different styles and types of pitches. By choosing the right typology for a specific case, it creates margins which allow one to focus on a single scenario, adapted for the given case, and in the right context of the situation. Some of the types mentioned in the studies are "The standard elevator pitch" [which] involves a one-minute proposal that provides an overview of a product or service, a company and a market with an explanation of why it might be attractive to investors", the "stadium pitch" which involves the idea that you are on a stadium and so to stop people from walking out of there, you have to interest them by different sensational moves and talks, and the last method "is the 'trade show,' sometimes called a venture exhibition. Prospective entrepreneurs develop their ability to demonstrate business concepts through a more visual means using prototypes, display boards and media - basically any means through which they can capture the attention of passers-by and get them to talk about the opportunity" (Pittaway, 2010, p. 14).

The above-mentioned types of pitches are beneficial for the right context and situation. In case of being one-on-one in some place and being short of time, an entrepreneur can use the first type of pitching, in case of presenting to an audience he/she can choose the second type of pitching and in case of being at some forumtype convention the entrepreneur can use the third type of pitching. The psychological strategy has to adapt to the situation and to the context and format of the environment in which the pitching is being made (Pittaway, 2010).

The last but not the least in this build-up of a psychological strategy for pitching is the theory of signals and how to apply it in a pitching process. The theory of signals in the process of persuading and trying to affect investors to give the needed capital is an applied method of separating and categorising different types of feelings and 
beliefs that the entrepreneur wants to transmit to the investor in an organised and systematic way. Such feelings and beliefs can be undertaken into groups of signals in the area of human capital signals (right organisation of management, for example), social capital signals (diversity, environmentally oriented, etc.), intellectual capital signals (patents, prototypes, business plans, budgeting, etc.), financial capital signals (positive growth, good financial statements, etc.). The quality of the signals is "best described as the linkage of the message being communicated from a signaler to the receiver and the signaler being able to actually carry out the requirements or promises of the message being sent" (Krukowski, 2019, p. 28). This is a thinking exercise which will allow the entrepreneur to underline the messages (signals) he/she wants to pitch to investors and to enforce his or her argumentation skills (Krukowski, 2019).

Pitching psychological strategies are not just an exclusive tool of entrepreneurs, but also the main instrument of the managers in corporations. The tactics of tailoring the speech, framing the issue, managing emotions, choosing the right timing, involving others, adhering to norms, and finally, suggesting solutions, are tactics recommended by Harvard Business Review. Researchers emphasise the urgency of fitting the right tactics in a smart combination and proper approach (Ashford \& Detert, 2015).

Pitching techniques are not so new, already in the middle of the 90s with the coming of information technologies, management started to search for different paths of pitching usability and everything involved within this concept and the new technological advances. The matter to be learnt from the past and newest experiences is that any idea or proposition within an organisation has to be studied and subjected to the executing resources in the most tactical way possible. If a communicator wants to succeed in promoting his or her idea, it is important to build up the basics and the values which will be communicated and yet not to forget to be prudent in the manner it is going to be disclosed towards the upstanding directors (Bloomer \& Croft, 1997).

\section{Conclusion}

Pitching is a very complex task which requires a psychological and strategic approach. To design a good influencing pitch, one has to embrace the vision of all the stages of the pitch and create a symbiosis of different scientific methodologies.

The psychologically effective and strategically though pitching design is separated into different parts, such as:

a. Defining the "type" of investor, so as to understand the personality of the audience.

b. Breaking the pitch into three parts: before pitching, while and after pitching.

c. Creating a good, by all standards, business plan and to use it as a basis for the audiovisuals. 
d. Preparing the right tones of voice so as to make a feeling of "passion" and to work on the charisma, i.e., working with the subliminal part of the investors's understanding.

e. Understanding fully the system of beliefs of the investors and how to use them for persuading in the most efficient way possible.

f. Adding and fulfilling the argumentation with the right content, which will have a stronger effect in combination with other techniques, like adding the microlevel argumentation.

g. Understanding the type of a pitch which is going to be most suitable for the environment and context.

h. Working on defining and adding the right signals which can give the investors the right beliefs regarding the management, social, or any other category of assurance of the investment project.

i. Psychological tactics of pitching are used in a very wide variety of fields, for instance angel investment, management, education, social issues, differentiated industries, marketing, and also science and research.

j. Pitching tactics is not something new, already in the middle of the 90s new information technologies were an important area of discussion and an ideological battlefield for the introduction of the upcoming millennium novelties. Already then pitching tactics were the newborn pushing factors of these innovations.

Therefore, with years, pitching became the basic soft skill in the business world. Business accelerators around the world spend hours on teaching young innovators how to pitch, create special meeting events with investors and show them how they have been learning this skill during the boot camp. It is understood that with the years to come, there will be revealing new and more efficient ways to influence investors psychologically to go into a project. Pitching is a new superstar in investment business and there are definitely many things to research and systemise in the near future.

\section{References}

Altizer, R., \& Zagal, J. (2014). Designing inside the box or pitching practices in industry and education. University of Utah. Retrieved from: http://www.digra.org/wp-content/ uploads/digital-library/digra2014_submission_134.pdf

Ashford, S., \& Detert, J. (2015, Jan-Feb). Get the boss to buy in. Harvard Business Review. Retrieved from: https://hbr.org/2015/01/get-the-boss-to-buy-in

Bloomer, S., \& Croft, R. (1997, Nov-Dec). Pitching usability to your organization. Interactions, 19-26. 
Cunningham, L. (2010). A Linguistic Analysis of the Entrepreneurial Pitch. Tiger Prints: Clemson University.

Ellis, P. (2016). To find a standard format that measures the activities of a Micro, Small or Medium Business Entity. A Pitch. Accounting and Management Information Systems, 15, 420-427.

Faff, R., Babakhani, N., Carrick, R., et al. ( (2017). Motivating Postgrad Research Students to Pitch their Ideas: What have we learned from "Pitching Research" Competitions at UQ? The University of Queensland. Retrieved from: https://www.researchgate.net/ publication/315034601_Motivating_Postgrad_Research_Students_to_Pitch_Their_ Ideas_What_Have_We_Learned_from_\%27Pitching_Research\%27_Competitions_ at_UQ

Faff, R., Ali, S., Atif, M., et al. (2017). Fantasy pitching. University of Wollongong. Retrieved from: https://ro.uow.edu.au/cgi/viewcontent.cgi?article=2580\&context=buspapers

Faff, R. (2015). A simple template for pitching research. Accounting and Finance, 55, 311-336.

Jadayel, R., \& Medle, K. (2018). The pitching concept in contemporary education. International Journal of Arts\&Sciences, 11(01), 1-10.

Krukowski, K. (2019). Pitching power: increasing alternatives through signals in new venture funding. Oklahoma State University. Retrieved from: https://core.ac.uk/download/ pdf/289096188.pdf

Maxwell, A. (2011). Business angel decision making. University of Waterloo. Retrieved from: https://uwspace.uwaterloo.ca/bitstream/handle/10012/6484/Maxwell_ Andrew.pdf?sequence $=1$

Meiklejohn, D. (2017). Documentary pitching, pre-sales, and funding: succeeding in a transforming digital landscape. Queens land University of Technology. Retrieved from: https://eprints.qut.edu.au/114129/

Mullainathan, S., \& Shleifer, A. (2005). Persuasion in finance. NBER Working Papers 11838, National Bureau of Economic Research, Inc.

Niebuhr, O., Tegtmeier, S., \& Brem, A. (2017). Advancing research and practice in entrepreneurship through speech analysis - from descriptive rhetorical terms to phonetically informed acoustic charisma metrics. Journal of Speech Sciences, 6(1), 3-26.

Peacock, G. (2016). Persuasive Pitching - Make Them Listen \& Win. Bennelong Publishing Pty Ltd.

Pittaway, L. (2010). Pitching for funds - the different routes. Georgia Southern University. Retrieved from: https://digitalcommons.georgiasouthern.edu/savannah/

Sherry, J. (1988). Market Pitching and The Ethnography of Speaking. Advances in Consumer Research, 15, 543-547.

Werven, R., Bouwmeester, O., \& Cornellissen, J. (2019). Pitching a business idea to investors: How new venture founders use micro-level rhetoric to achieve narrative plausibility and resonance. International Small Business Journal: Researching Entrepreneurship, 37(3), 193-214. 
Wickert, C., \& Bakker, F. (2015). Pitching for social change: towards a relational approach to selling and buying social issues. Academy of Management Discoveries, 4(1), 50-73. Williams, A. (2013). A study on the art and science of pitching new businesses. MIT Sloan School of Management. Retrieved from: https://dspace.mit.edu/handle/1721.1/80674

\section{Oleg Redko}

Research student at a $\mathrm{PhD}$ degree programme in the Department of Economic Theory at Kyiv National Economic University named after Vadym Hetman, Ukraine. He has a Bachelor's degree in Business Administration and a major in Management, holds a Bachelor's in Psychology and a Specialist degree in Practical Psychology, he also holds a Master's degree in Management of Innovations. His professional experience involves innovations, business consulting, and new markets penetration.

e-mail: redko.industries@gmail.com

ORCID: 0000-0002-7425-7154

\section{Oleksandra Moskalenko}

Professor, Dr of Sc in Economics, Professor in the Department of Economic Theory at Kyiv National Economic University named after Vadym Hetman, Ukraine. She is the author of about 100 articles in Ukrainian and foreign scientific journals, as well as the following books: Theory and Model of Advanced Economic Development in the System of Social Strategic Needs (2014) and Contemporary Political Economy as a Theoretical Basis of Economic Development of the Society (2018; 2020).

e-mail: oleksandra.moskalenko@kneu.edu.ua

ORCID: 0000-0003-1036-5356 